\title{
Applications of Bacterial Cellulose in Food, Cosmetics and Drug Delivery
}

\section{Ullah, Hanif}

2016-08

Ullah , H , Almeida Santos , H \& Khan , T 2016 , ' Applications of Bacterial Cellulose in Food, Cosmetics and Drug Delivery ' , Cellulose , vol. 23 , pp. 2291-2314 . https://doi.org/10.1007/s10570-016-0986-y

http://hdl.handle.net/10138/327360

https://doi.org/10.1007/s10570-016-0986-y

acceptedVersion

Downloaded from Helda, University of Helsinki institutional repository.

This is an electronic reprint of the original article.

This reprint may differ from the original in pagination and typographic detail.

Please cite the original version. 
Applications of bacterial cellulose in food, cosmetics and drug delivery

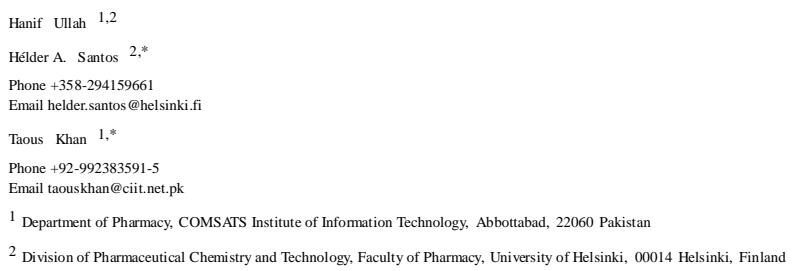

Abstract

Bacterial cellulose $(\mathrm{BC})$ is a versatile biopolymer with better material properties, such as purity, high degree of porosity, relative high permeability to liquid and gases, high water-uptake capacity, tensile strength and ultrafine network. This review explores the applications of $\mathrm{BC}$ and its hydrogels in the fields of food, cosmetics and drug deli very. Applications of BC in foods are ranging from traditional dessert, low cholesterol diet, vegetarian meat, and as food additive and dietary aid to novel applications, such as immobilization of enzymes and cells. Applications in polymer based enantioselective drug delivery anseal cleansing formulations and contact lenses. BC for controlled drug delivery, delivery could be further fine-tuned to get more sophisticated control on stimuli-responsive drug release. Along with the currently available literature, further experiments are required to obtain a blueprint of drug in vivo performance, bioavail ability and in vitro-in vivo correlation.

Keywords

Bacterial cellulose

Cosmetics

Deracemization

Drug delivery

Food

Nutraceuticals

Protein delivery

Introduction

Biomaterials play a vital role in the daily life of humans (Czaja et al. 2007; Hubbell 1995; Ratner and Bryant 2004; Shoichet 2009). The importance of biopolymers in our food applications, and personal and medical care cannot be ruled out (Ellis and Smith 2008; Murphy 2001; Jay ef al. 2008). Cellulose is the most abundant biopolymer on the surface of earth with $1.5 \times 10^{12}$ tons annual production (Czaja et al. 2004; Klemm et al. 2005), and most commonly it is obtained from plants (Siró and Plackett 2010).

In addition to plant cellulose (PC), cellulose is also obtained through in vitro synthesis with the help of enzymatic pathways, the chemical synthesis from glucose derivatives and the biosynthesis by various microorganisms, such as algae and fungi (Klemm et al. 2005), as well as various aerobic non-pathogenic bacteria of the genera Agrobacterium, Sarcina, Rhizobium and Acetobacter (Dufresne 2013; Khan et al. 2007; Shezad et al. 2010). While studying acetic fermentations in 1886, Brown reported the bacterial cellulose (BC) in the form of a strong white gelatinous pellicle on the surface of a liquid medium, which had a thickness up to $25 \mathrm{~mm}$. The microbe responsible for this BC membrane (BCM) was called Bacterium xylinum that was later on renamed as Acetobacter xylinum (A. xylinum) and at the moment is recognized as Gluconacetobacter xylinus (G. xylinus) (Brown 1886a, b).

G. xylinus is the most extensively used microorganism in the basic and applied studies for BC production because of its higher productivity, and capability to consume different sugars and other compounds as sources of carbon (Ross et al. 1991; Saxena and Brown 2012). G. xylimus cultivated under controlled conditions with suitable nitrogen and carbon sources, produces highly porous BC network structures in the form of sheets or pellicles, subject to the culturing approach (Lin et al. 2013; Pircher et al. 2014). The culturing conditions may be agitated or static, to glucose-1-phosphate: (c) glucose-1-phos phate is converted to uridine diphosphate glucose (UDP-glucose); and (d) finally glycan chynthesis of BC occurs in four enzymatically catalysed steps: (a) glucose is phosphorylated to glucose-6-phos phate; (b) glucose-6-phosphate is isomerized followed by aggregation of the latter to discontinuous bundles of cellulose fibres (Iguchi et al. 2000; Lin et al. 2013). After removal of the culture medium and complete washing, colourless, odourless and tasteless BC is obtained in the form of a gel. This gel finds several applications our life (Lin et al. 2013). The biosynthetic pathway of BC in G. xylinus is shown in Fig. 1.

Fig. 1

Biosynthetic pathway of BC in G. xylinus.

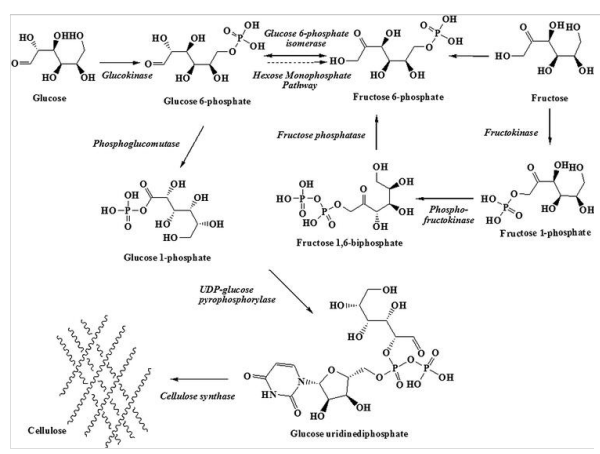

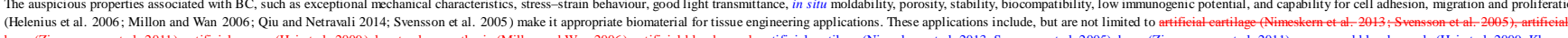

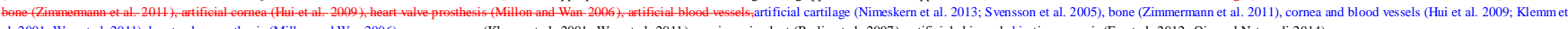
al. 2001; Wan et al. 2011), heart valve prosthesis (Millon and Wan 2006), nerve surgery (Klemm et al. 2001; Wan et al. 2011), meniscus implant (Bodin et al. 2007), artificial skin and skin tissue repair (Fu et al. 2012; Qiu and Netravali 2014)

Some of these BC-based applications of BC are shown in Fig. 2.

Fig 2

Applications of $\mathrm{BC}$ in biomedicine

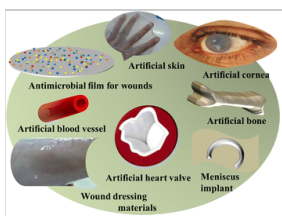

However, in the current review, we have focused mainly on the applications of $\mathrm{BC}$ in various fields, ranging from conventional food to modern functional foods, cosmetics, nutraceuticals, cosmeceuticals and drug delivery. This review will provide the readers an understanding of the role of BC as a functional additive, formulation stabilizer, biocatalysts platform, and ingredient for food, cosmetics and drug delivery systems. Furthermore, the review will be helpful for academic researchers and formulation scientists in food, cosmetics and pharmmceutical industries to give new insights to BC in terms of designing some novel BC-based functional foods, nutraceuticals, cosmeceuticals and drug deli ery systems.

Better material properties of $\mathrm{BC}$ for food cosmetics and drug delivery applications

Although similar in chemical structure, BC has different and superior physical, mechanical and biological features to PC. Due to these superior properties, it finds applications in food, cosmetics, biomedicine and drug delivery (Lin et al. 2013). BC is biosynthesized in its purest form, which is entirely devoid of pectin, hemicelluloses and lignin (Chawla et al. 2009). Hence, BC is capable to be easily refined in comparison to PC (Shi et al. 2014b). As-synthesized, innate or pristine BC is highly porous in nature with high permeability to liquid and gases, and possesses high water-uptake capacity (more than $90 \%$ of its weight) (Klemm et al. 2001). These characteristics of BC are due to the ultrafine network of the ribbon-shaped micro- and nanofibrils (Chawla et al. 2009), which are about 100-fold more thinner than the PC fibres. Such properties of BC make it suitable for application as formulation stabilizer, thickener, and for scrubbing and exfoliation without damaging the skin due to its soft texture of small fibres (Lin et al. 2015; Shi et al. 2014b). Moreover, the biocompatibility, low immunogenic potential and in situ foldability further enhance the applicability of BC in the field of biomedicine (Lin et al. 2016). These properties together with tensile strength (Campano et al. 2015) make BC a suitable candidate for dermal applications in cosmetics, and topical and transdermal drug delivery. Due to high water holding and ion exchange capacities, BC is an appropriate material for laxative effects and low cholesterol diet, respectively. Similarly, the transparency (Campano et al. 2015), along with high permeability to liquid and gases, makes BC an appropriate agent for facial mask, contact lenses
and drug deli very to wound with ease of wound inspection (Czaja et al. 2006). The individual fibre strength of BC is al most comparable to that of Kevlar and steel (Yano et al. 2005), making it suitable candidate for applications, where high tensile strength is required, eg. drug loaded bone cent Serat

Fig. 3

Better material properties of $B C$ 


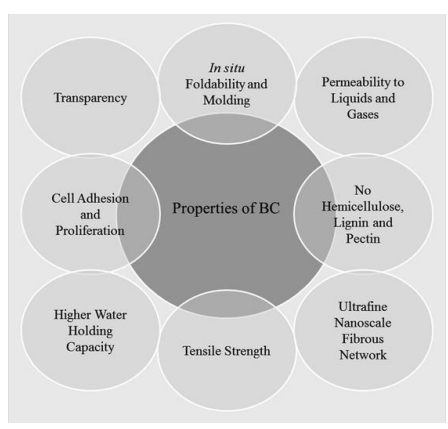

The material properties of $\mathrm{BC}$ can be further tailored by using various in situ techniques, such as addition of various substances, change in culturing conditions and the use of genetically modified strains, and ex situ strategies like physical and chemical modification, specialized drying conditions and electromagnetic irradiation (Krystynowicz et al. 2002; Lin et al. 2013, 2016; Olyveira et al. 2013; Petersen and Gatenholm 2011; Stoica-Guzun et al. 2007; Sulaeva et al. 2015; Yadav et al. 2010).

Applications of $\mathrm{BC}$ in food, cosmetics and drug delivery

Due to the abovementioned properties, BC finds various applications in foods, cosmetics and drug deli very. These applications are discussed with details in the following sectionsections and are summarized in Fig. 4.

Fig. 4

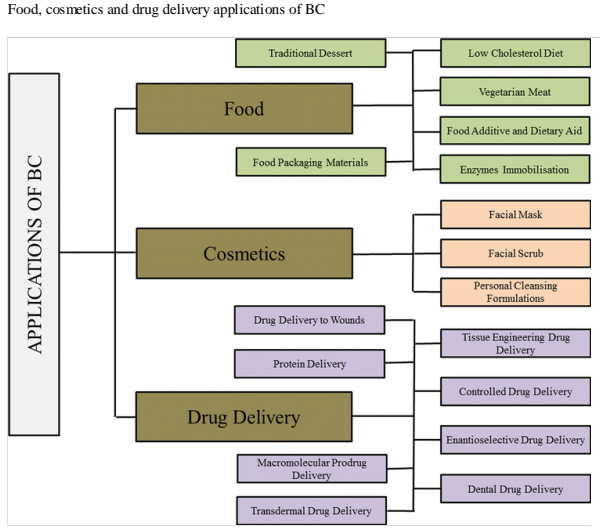

Food applications

Being a dietary fibre, BC is considered "generally recognized as safe" (GRAS) by the Food and Drug Administration (FDA) since 1992 (Shi et al. 2014b; Park et al. 2009). BC possesses manifold potentialities in food industries owing to its high purity, a variety of textures and shapes (e.g., particles, spheres, filaments, multi-shaped pulps, films and whiskers), capability to acquire in situ changes, such as colours and flavours of culture medium, and easy production process (Shi et al. 2014b). Keeping in view the abovementioned properties, BC can be used as adjuvar in foods and food industry.

Traditional dessert One of the first uses of $B C$ is the manufacturing of a Filipino traditional dessert with a smooth mouth feel that is called 'nata de coco', whereby coconut water is fermented for the biosynthesis of BC, then the BC is chopped into minute sections and immersed in syrup of sugar. This 'natt
de coco' is used as a sweet candy dessert (IIguchi et al. 2000; Klemm et al. 2005, 2006). The 'nata de coco' has turned into a very well-liked food and is now quickly spreading worldwide in the form of a dessert or candy (Gamm

Low cholesterol diet

BC possesses higher water-holding and cation-exchange capacities than PC with significant serum lipids and cholesterol lowering effect. Thus, fat free, low-cholesterol and low-calorie food conmodities can be made with BC (Chau et al. 2008). It might also be employed as a potential candidate to replace the fat in end $\mathrm{w}$ ith sugr a w with alginate and calcium chloride or with sugar alcohol. The textures of such BC resemble molluscs and fruit, such as squids and grapes, r r
cutting off with the teeth. These facts make BC a new material for processed foods, low-calorie desserts and salads (Okiyama et al. 1992).

Vegetarian meat

Vegetarian meat may be prepared by using BC in combination with Monascus extract obtained from a natural red pigmented mould (Purwadaria et al. 2010). The composite is stable against changes in colour and morphology, and its flavour is much like natural meat (Jủzlová et al. 1996; Wonganu and Kongruang 2010). The vegetarian meat adds cholesterol-lowering effect to the other advantages of BC dietary fibres (Ng and Shyu 2004). Moreover, due to non-animal origin, this meat could be a suitable substitute to animal-based products for certain consumers with dietary restriction

Food additive and dietary aid

BC has also been explored for its use as a potential gelling, thickening, suspending and stabilizing agent in the food industry (Shi et al. 2014b). BC also acts as a heat-stable suspending agent, and as a filler for the reinforcement of fragile food hydrogels, improving the worth of pasty foods by decreasing their stickiness (Okiyama et al. 1992). Moreover, BC (0.2-0.3\%) significantly increases the gel strength of Tofu (food made by coagulating and pressing soy milk), providing firmness and better texture. BC has also endowed Kamaboko (processed Japanese seafood) with better stiess a the latter could be noticeably improved so that it would be easier to serve it quantitatively using a spoon (Shi et al. 2014b). Similarly, food items having BC can maintain their humidity for minimum storage period of 1 monnth. The contour of ice-cream having BC was maintained for at least 60 min after it was removed from freezer, which would otherwise melt over the same time in the absence of $\mathrm{BC}$ (Shi et al. 2014b) Hence it is evident that $\mathrm{BC}$ could be extensively used in processed foods to improve the stability over a wide range of temperature, $\mathrm{pH}$ and freeze-thaw environments. These findings further clarify that BC could be widely applicable to processed foods to improve their quality and storage conditions.

Enzymes and cells immobilization

The production of high amount of food needs the use of modern technologies. Immobilization of enzymes and cells is one of such technologies. In case of certain food items, fermentation industry has been greatly assisted by the application of immobilized enzymes that can change severa of their functioning parameters (Kilara et al. 1979; Fernandes 2010).

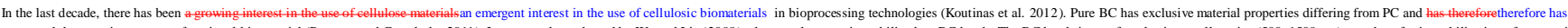
engrossed the attention as a new functional biomaterial (Petersen and Gatenholm 2011). In a research conducted by Wu and Lia (2008), glucoamylase was immobilized on BC beads. The BC beads in wet form having smallest size (500-1500 $\mu \mathrm{m}$ ) were best for immobilization of enzyme in comparison to other types of $\mathrm{BC}$ beads. The stability of enzyme was increased against changes in lower temperature and $\mathrm{pH}$ values (Wu and Lia 2008). Likewise, the activity of immobilized enzyme via periodate oxidation method was increased by ca. $40 \%$. Being pH- and temperaturedependent, there was still ca. $46 \%$ of the activity after 14 times of repeated use (Wu et al. 2013). Some other researchers used yeast for repeated batch fermentation for wine-making that was immobilized on BC. The immobilized yeast promoted the cost effectiveness of the manufacturing process by reducing the expenses for preparation of inoculum, whereby the yeast was recovered by simple separation at the end of the fermentation process (Nguyen et al. 2009; Ton and Le 2011). No significant difference was found for ethanol yield by yeast immobilized either on BC or calcium alginate (CA) (Montealegre et al. 2012). However, in another study, Kirdponpattara and Phisalaphong (2013) immobilized yeast using composites of BC with CA (BC-Al) with high chemical, thermal and mechanical stability, suitable porosity, pore size and hydrophilicity. Thus.
in terms of ethanol production, the yeast immobilized on BC-Al substrate was more efficient than the suspended culture and culture immobilized on CA matrix. The efficient ethanol production can be ascribed to the water uptake capacity and properly interconnected porous structure in terms of ethanol production, the yeast immobilized on BC-Al substrate was more efficient than the
responsible for appropriate mass transfer during the process (Kirdponpattara and Phisalaphong 2013).

BC-based composites can be used for warious important enzymes and cells immobilization. Similarly, the immobilization of Corynebacterium glutamicum using BC as a support was carried out by adsorption and subsequent incubation for the synthesis of L-lysine (Tam and Huong 2014). The immobilized cells were used eight times for repeated fermentation. The lysine yield was $95 \%$ in the eighth repetition of reusing immobilized cells. Regarding stability and cell viability, the immobilized cells had 80 \% cell survival in sterile water (pH 7 ) stored at $40{ }^{\circ} \mathrm{C}$ for 30 days (Tam and Huong 2014).

Laccases obtained from different sources are extensively used in food industry (Osma et al. 2010). These laccases find applications in improving the organoleptic properties of foods, such as the colour of tea-based products, the stability of the beer and wines, the taste and flavour of cacao nib, and the flavour and colour of some vegetable oils. Laccase may also improve the quality of certain foods, such as sauces, pastes, puree, concentrates, and soups by the process of deoxygenation (Osma et al. 2010 ). Likewise, it has been used to decrease the bitterness and darken the

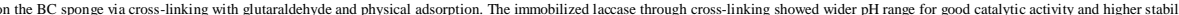
in comparison to free as well as adsorbed one. The immobilized laccase retained $69 \%$ of its original activity after 7 cycles (Chen et al. 2015).

Furthermore, BC has been used for immobilization of enzymes, such as horse radish peroxidase, glucose oxidase and laccase for biosensors, bioanalysis and enzymatic biofuel cell (Chen et al. 2011; Lvet al. 2016; Wang et al. 2010; Zhang et al. 2010), which is beyond the scope of this review.

From the aforementioned literature, it is evident that BC beads and cubes have potential for the immobilization of enzymes and cell systems for improving yield, quality and stability of food product in food industry. Moreover, these studies show the potentials of BC for the immobilization of other enzymes in techno-economically feasible manner for food production.

Food packaging

BC works as a food packing to confirm the safety and increase shelf-life of the products. Antimicrobial ingredients, ethylene and oxygen scavengers, and moisture and taint removers are all used in active BC-based packaging systems (Tomé et al. 2010). Moreover, modified BCM with tailored surface and bartier properties have been prepared by controlled heterogeneous esterification with hex.

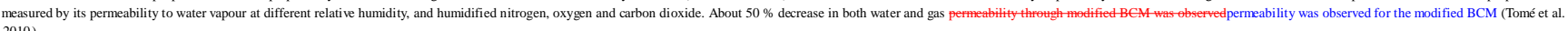

Furthermore, Jipa et al. (2012) designed biodegradable BC and sorbic acid (BC-SA) based monolayer and multilayer films by incorporation of SA as antibacterial agent. The study showed that concentration of both BC and SA affected the sensitivity to water, rate of SA release, and the formed SA (Jipa et al. 2012).

Similarly, composite materials with antimicrobial activities were designed, whereby poly(vinyl alcohol) (PVA) acted as polymeric matrix and grinded BC as reinforcing fibres (Dobre et al. 2012). SA was

industry. The designed film showed antibacterial effect against Escherichia coli (Dobre et al. 2012), which revealed that new composite film could be promising antimicrobial material for food packagin

From the above discussion, it is evident that BCM is a promising and interesting biopolymer for the development of materials with potential applications in the packaging industry with antimicrobial property and durability

Studies related to applications of $\mathrm{BC}$ in food and food industry are summarized in Table 1. 
Table

\begin{tabular}{|c|c|c|c|}
\hline Fool, related iten or process & Forn of $\mathrm{BC}$ & Pupose of BC & References \\
\hline Nata de coco & BC slices & Main structure & Iguchi et al. (2000) \\
\hline Low cholesterol diet & Powdered BC & Fat adsorbent & Chau et al. (2008), Lin and Lin (2004), Stephens et al. (1990) \\
\hline Vegetarian meat & BC sheets & Structural component, fat adsorbent & Juzzlová et al. (1996), Purwadaria et al. (2010), Wonganu and Kongruang (2010 \\
\hline Pasty food and jams & Aqueous paste & Heat-stable suspending and bulk forming agent & Okiyama et al. (1992) \\
\hline Tofu & Aqueous paste & Gelling agent & Okiyama et al. (1993) \\
\hline Kamboko & Aqueous paste & Hardening agent, texture modifier & Okiyama et al. (1993) \\
\hline Chocolate drink & Aqueous paste & Stability against heat & Okiyama et al. (1993) \\
\hline Ice-cream & Aqueous paste & Hardening agent, stability against freeze-thaw process & Okiyama et al. (1993) \\
\hline Glucoamylase & Beads & Solid support to increase enzymatic activity & Wu and Lia (2008), Wu et al. (2013) \\
\hline Wine & BC pieces & Solid support to increase activity of yeast & Montealegre et al. (2012), Nguyen et al. (2009), Ton and Le (2011) \\
\hline Fungal laccase & $\mathrm{BC}$ sponge & Solid support to increase activity of laccase & Chen et al. (2015) \\
\hline L-lysine & $\mathrm{BC}$ cubes & Solid support to increase activity and cell viability & \\
\hline Food packaging & BC sheets, film an & Hydrophobic and antimicrobial packaging & Dobre \\
\hline
\end{tabular}

Cosmetics applications

Cosmetics are substances that are used to improve some of the organoleptic properties of the human body (Hasan et al. 2012). Cosmetics include products that are applied to the human body for altering the appearance, enhancing the attraction, and cleansing or beautifying the body parts
without sffecting the normal body functions or structure (Hasan et al. 2012 ) Currently the majoity of the cosmetics are used by customers to boost their beauty without bearing in mind the illeffects on body. for example, toxicity concerms associated with parabens (Nagel et al. 1977 ; without affecting the normal body functions or structure (Hasan et al. 2012). Currently, the majority of the cosmetics are used by customers to boost their beauty without bearing in mind the ilh
Darbre and Harvey 2008). In order to avoid harmful effects to the consumers, natural skin-care products are recommended, which utilize herbal or natural ingredients (Hasan et al. 2012).

In this context, cellulose fibrils are applied in cosmetics to stabilize oil-in-water (O/W) emul sion without the addition of any of surfactant. Such formulations may not be irritant to sensitive skin due to the absence of any surfactant (Hasan et al. 2012). BC has also been reported to be an exceptional non-allergenic biopolymer for use in the cosmetics. The various application of BC in cosmetics are discussed in the following sections.

Facial mask

BC facial masks are of great interest as cosmetic devices to treat dry skin due to its biodegradability, low toxicity and ability to hydrate the skin (Amnuaikit et al. 2011). In a study, one group of volunteers was asked to applyput moist towels teon the face for 25 min, while the second group was assigmedallocated to apply the translucent BC facial masks for the same period (Amnuaikit et al. 2011). During the subsequent week, the groups were interchanged to the alternative treatment. Skin dullness, texture, elasticity, sebum content, moisture content and desquamation
levels were eval uated using a system used for routine skin counselling before applying and after 5 min of removing the towels and trial product (Amnuaikit et al. 2011). The user satisfaction about the BC mask was also investigated. The BC masks augmented the moisture contents of the

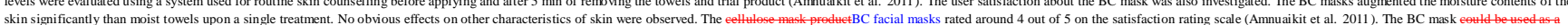
skin significantly than moist towels upon a single treatment. No obvious effects on other characteristics of skin were observed. The cellulose mask product BC facial masks rated around 4 out of 5 on the satisfaction rating scale (Amnuaikit et al. 2011). The BC mask emuld be used

Similarly, BC with and without glycerine was evaluated for skin irritation potential in human subjects (Almeida et al. 2014). There was no significant difference in terms of transepidermal water loss (i.e., absence of barrier disruption) and erythema with zero clinical score, except for few subjects with mild skin irritation. Moreover, addition of glycerine gave a significantly higher skin moisturizing effect, suggesting its potentials for moisturizing facial mask (Almeida et al. 2014).

In a patent, BC facial mask was fabricated with holes for eyes, mouth and nose (Zhong 2008). The author claimed that such mask may be suitable for repeated or prolonged use for skin beautifying purpose, skin nutrition, and moisturizing and cosmetic effects (Zhong 2008). Similarly, facial mask composed of BC membrane containing ginseng extracts has shown promising results in terms of moist feel, overall user satisfaction and skin elasticity in women over 30 years of age (Lee et al. 2011 ). In another study, BC facial mask with sodium bicarbonate ( $5 \mathrm{~g}$ ), 2 ang BC gel with controlled release of silk sericin were developed with improved moisture holding capability in comparison to commercially available paper mask (Aramwit and Bang 2014). Upon peel test using porcine skin, it was revealed that BC-based gel was biocompatible and less BC gel with controlled release of silk sericin were developed with improved moisture holding capability in comparison to commercially avalable paper mask (Aranwit and Bang 2014). Upon peel test usin
adhesive (peeled without pain) than paper mask (Aramwit and Bang 2014). The prepared gel may find potential applications in medicated cosmetics as anti-wrinkle, antiaging and moisturizing facial mask.

Keeping in view the

Facial scrub and medicated cosmetics

A facial scrub containing powdered BC and natural ingredients including olive oil, ascorbic acid (Vitamin C), Aloe vera extract and powdered glutinous rice was formulated (Hasan et al. 2012). Using plate-plate rheometer, both commercial and formulated facial scrubs showed shear thinning behaviour (non-Newtonian liquid). The formulated facial scrub possessed relatively higher viscosity at lower shear rates in comparison to the commercial one, but both possessed nearly comparable viscosities at higher shear rates. The tested samples were capable of drying out after 10 min at $\sim 30^{\circ} \mathrm{C}$ (room temperature). This novel formulated facial scrub containing BC as major ingredient engrosses the attention of cosmetics formulators for the development of facial scrub with natural ingredients, making it safe for skin. Moreover, Lin et al. (2015) claimed
cosmetic containing fragments of $\mathrm{BC}$ film in the range of $0.05-1.0 \%$ by weight. By adding the fragenents of $\mathrm{BC}$ in the cosmetic not only improved the transdermal permeation of active ingredients present in the cosmetic. but also provided skin moisturizing function, sebum absorption at skin exfoliation (Lin et al. 2015). It has also been claimed that due to high water holding capacity and good gas permeability, BC is an appropriate carrier for cosmetically active ingredients including moisturizers, such as salicylic acid or hyaluronic acid whitening ingredients, such as kojic acid or ursolic acid, anti-wrinkling agents (e.g.g., polypeptides, and exfoliator). growth factors, enzymes, or a combination thereof (Lin et al. 2015). Moreover, according to authors (Lin et al. 2015; Tournilhac and Lorant 2003). BC-based formulation can find extensive applications in designing the lip, skin and nail care products and long-lasting perfume.

Personal deansing formulations

The purpose of personal cleansing formulations is remove dirt, reduce sebum and exogenous contaminants, and to control mal odour and the skin microflora. In addition to hygienic benefits, surfactants in such formulations damage skin constituents and may entangle in the stratum comeu after washing (Kuehl et al. 2003; Walters et al. 2012). This can lead to allergic reactions and skin irritation, especially in case of sensitive skin (Draelos et al. 2013; Kuehl et al. 2003). In this regard, BC prodtueedbiosynthesized in agitated culture conditions (Ag-BC) shewedexhibited the highest stabilizing effect for $\mathrm{O} / \mathrm{W}$ emulsion among all the inspected cellulose-based materials (Ougiya et al. 1997). It was demonstrated that BC fine fibrils acted as a scaffolding structure and a mechanical barrier, interrupting the coalescence of oil droplets. Thus, the emulsion was
stabilized without reducing the interfacial tension as occurs in the case of surfactants (e.g.g. sorbitan monolaurate). Due to its thinner fibrils, Ag-BC would protect a larger surface area of the droplets of oil in the form of mechanical barrier than any other cellulose-based material. Moreover, stabilized without reducing the interfacial tension as occurs in the case of surfactants (e.g., sorbitan monolaurate). Due to its thinner fibrils, Ag-BC would protect a larger surface area of the droplets of oll in the form of mechanical barrier than any other cellulose-based material. Moreover,
this emul sion was also stable against changes in temperature and $\mathrm{pH}$, and against addition of salt in comparison with xanthan gum- and sorbitan monolaurate-based formulations. One of the potential applications of this $\mathrm{O} / \mathrm{W}$ type emul sion could be the formulation of body parts cleansing products, especially for sensitive ski

In a patent, a personal cleansing formulation consisting of liquid matrix, i.e., water, a lathering surfactant and an external structuring agent, comprising both $\mathrm{BC}$ network and a cationic polymer e.g., cationic starch derivatives and cationic cellulose derivatives or mix tures of these, was claimed to be formulated (Heath et al. 2012). The particles of these formulations were suspended in the liquid matrix with pH-values of less than ca. 4.0 or 7.0. Such compositions provided good lathering and easily rinse off properties without any unwanted filmy or slimy hand feel. The presence of particulate matters improve cleansing and exfoliation with conditioning benefits, and without any irritation or damage to the skin. A pH-val ue less than ca. 4.0 is especially preferred for salicylic acid formulations (Heath et al. 2012). Such formulation may be used for body
cleansing for sensitive skin without any irritation, especially for body parts, where consumer's hand feel is important. Moreover, using compositions of such formulation at pH-value of less than ca. 4.0, salicylic acid formulation for personal cleansing can be formulated. Such formulation may be used to clear and prevent skin blemishes and pimples. These may also be used for the treatment of skin conditions with scal ing or skin overgrowth (Heath et al. 2012).

Contact lenses

Other than optical indications, contact lenses find wide range of applications including cosmetic or decorative purpose (Rubinstein 2003; steinemann et al. 2005). BC is one of the potential candidates for fabrication of contact lenses due to its transparency, light transmittance, and permeability to liquid and gases. BC-based contact lens was fabricated by pouring high viscosity BC solution (in 1-butyl-3-methylimidazolium chloride) to a mould. Upon treating the solution with isopropyl alcohol followed by water, a clear BC membrane was precipitated, whispontaneously detached from the mould surface and the residual solvent diffused to the water. The hydrated BC contact lens retained its shape and transparency for a time of more than 8 weeks (Levinson and Glonek 2010$)$. Similarly, transparent polymeric hydrogel was prepared by contact lenses can find potential applications for drug delivery to the cornea. Moreover, the ability of BC to take colour of the medium (Shi et al. 2014b) can be exploited for design of coloured and appealing contact lenses with transparent centre for the pupil, provided that the biocompatibility is not compromised by the colourant(s).

The applications of BC and BC-based products in cosmetics are summarized in Table 2.

Table 2

Applications of BC in cosmetics

Cosmetic product

Facial mask

Facial mask

Faciifacial mask

Facial mask

Facial mask

Facial scrub

Facial scrub

Carrier for cosmetically active ingredients

Foundation make-up

Personal cleansing product

Contact lenses

Contact lenses

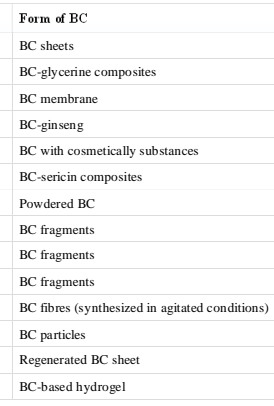

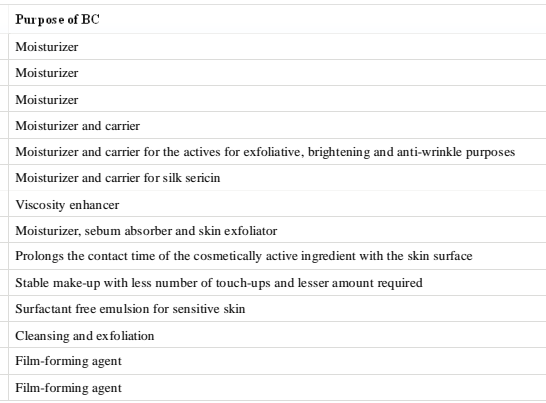

(a)

hong (2008)

Aramwit and Bang (2014)

Hasan et al. (2012)

Lin et al. (2015)

Lin et al. (2015)

Lin et al. (2015)

Ougiya et al. (1997)

Heath et al. (2012)

Levinson and Glonek (2010)

Li et al. (2010)

Drug delivery applications

Drug delivery to wounds

Studies have suggested that fluid, particularly exudates from chronic wounds may inhibit healing process (Vowden and Vowden 2003). An excessi vely wet environment may lead to wound and skin maceration resulting in prolonged wound healing, whereas a dry wound will also heal mor gradually due to lack of moisture required for cell migration (Benbow and Stevens 2010). Hence, exudates reduction looks like a key parameter for normal healing process (Sulaeva et al. 2015). Being an excellent absorbent (Gayathry and Gopalaswamy 2014) and skin moisturizer
(Amnuaikit et al. 2011), BC can be an ideal candidate for lowering or removing the wound exudates, while at the same time maintaining a moist environment (Sulaeva et al. 2015). However, innate BC is devoid of antimicrobial activity against the wound deteriorating pathogens.

To achieve such goals, a BC film with antibacterial property was fabricated, whereby a lyophilized BC film was dipped in a benzalkonium chloride (BZK) solution followed by further lyophilization (Wei et al. 2011). Water uptake capacity, a feature important for wound dressing system. To achieve such goals, a BC film with antibacterial property was fabricated, whereby a lyophilized BC film was dipped in a benzalkonium chloride (BZK) solution followed by further lyophilization (Wei et al. 2011$)$. Water uptake capacity, a feature important for wound dressing system,
was also attained with a swelling ratio of 37.3 and 26.2 for saline solution and deionized water, respectively. A prolonged (at least $24 \mathrm{~h}$ ) stable antibacterial activity was achieved against Staphylococcus aureus along with a higher water uptake capacity. Thus, BZK-loaded BC film may act was also attained with a swelling ratio of 37.3 and 26.2 for saline solution ann
as a potential functional wound dressing system for treatment of acute traumas.

Recently, Pavaloiu et al. (2014b) studied the release of the antibiotic amoxicillin (AMX) from BCM at nearly neutral (7.4) $\mathrm{pH}$ conditions. The concentration of AMX significantly influenced the drug release (Pavaloiu et al. 2014b). Among the other factors, there was a significant contribution of glycerol (as plasticizer) to in vitro drug release. The common topical drug deli very enhancer cetyl trimethyl ammonium bromide did not show any positive impact on the in vitro release of the drug. This system might provide a suitable way for antibiotic delivery to the wound.

The antimicrobial activity of antibiotics with prolonged drug release behaviour from BC was assessed in vitro using ampicillin (AMP) and gentamycin (GM) (Kaplan et al. 2014). For the assessment of exudate retention, the water uptake capacity of the BCM was found to be $65.6 \pm 1.6 \%$ in phosphate buffer saline (PBS). The drug loading was 99 and $48 \mathrm{mg} / \mathrm{cm}^{2}$ for AMP and GM, respectively. The BCM released only trace amount (0.107 \% of AMP and $0.113 \%$ of GM) within $24 \mathrm{~h}$. Thus, with no burst release, the amount of drug released within 7 days was 28 and $17 \%$ for

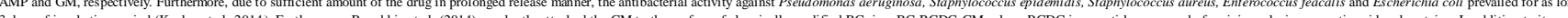
3 days of incubation period (Kaplan et al. 2014). Furthermore, Rouabhia et al. (2014) covalently attached the GM to the surface of chemically modified BC, i.e., BC-RGDC-GM, where RGDC is a peptide composed of arginine, glycine, aspartic acid and cysteine. In addition to it (Stoca-Gil good epithelialial for safety through in vitro cytotoxicity haemolysis, sensitization in ginea for safety through in vitro cytotoxicity, haemolysis, sensitization in guinea pigs, irritation potential in rabbits and acute systemic toxicity (Serafica et al. 2010). In addition to good antimicrobial effects, wound heal ing in animal models showed that the BC-PHMB wound dressing
rehabilititeded $70 \%$ of the wounds in comparison to 0,20 and $50 \%$ for the air-exposed, hydrogel treated and hydrocolloid treated wounds, respectively. Upon clinical effectiveness testing in humans, BC-PHMB showed promising results for wound healing of deep pressure wounds an rehabilitated $70 \%$ of the wounds in comparison to 0,20 and $50 \%$ for the air-exposed, hydrogel treated and hydrocolloid treated wounds, respectively. Upon clinical effectiveness testing in humans, BC-PHMB showed promising resul
venous leg ulcers (Serafica et al. 2010). Furthermore, in patient, this wound dressing system was more promising than the other commercial dressing in terms of bacterial load reduction and pain management (Haemmerle et al. 2012). 
Though not a drug deli very system, BC has also been investigated as promising antimicrobial film for wound dressing with various agents, such as deacetylated chitosan (Butchosa et al. 2013), chitosan (viral protective membrane) (Wanling et al. 2012), montmorillonite (UI-sllam et al 2013), and nanoparticles of silver (Dobre and Stoica-Guzun 2013), copper (Pinto et al. 2013) and titanium dioxide (Khan et al. 2015). However, such metallic nanoparticles are infamous due to their possible concerns with human health, such as hepato-, neuro-, photo-, geno-, cyto- and
dermal toxicity, formation of oedema, and hyperplasia (Koohi et al. 2011; Lu et al. 2010; Prabhu et al. 2010; Ray et al. 2009; Samberg et al. 2010; Wang and Wang 2014; Wang et al. 2014). The histopathological changes in the bones, hearts and kidneys of guinea pigs, and lack of studies about toxic effects with prolonged use of such nanoparticles further limit their practical applications (Korani et al. 2013 ).

Tissue engineering drug delivery

BC-based materials have also been demonstrated for drug delivery applications in the field of tissue engineering and regeneration. In this scenario, Mori et al. (2011) studied the release of antibiotics (GM and vancomycin) from a BC-based bone cement. It was demonstrated that

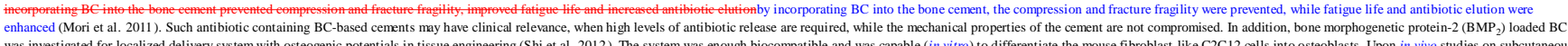
implants, the BMP 2 loaded BC scaffold was capable for bone formation with higher calcium concentration than the pristine BC scaffolds (Shi et al. 2012). Hence, it can be concluded that BC is a good carrier for localized delivery of therapeutic candidates, such as BMPs in tissue engineering

Controlled drug delivery

Frequent dosing, fluctuation in plasma drug concentration and patient non-compliance associated with shorter half-lives of drugs necessitate such drugs to be formulated into controlled release dosage forms. Researchers have made some attempts in order to control the drug release from
BC-based deli very systems. For this purpose, Amin et al. (2012a- $b$ (2012a) reported the use of powdered BC to coat paracetamol tablets using a spray-coating technique (Amin et al. 2012a). The study demonstrated that BC formed hi hig-qual ity. foldable, flexible and uniform soft films without adding any plasticizer that was comparable to the film of ethyl cellulose aqueous dispersion (Aquacoat ECD). In vitro drug release rate was dependent on the BC film thickness and was slower (200 min for maximum release) for coated tablets with $200 \mu \mu \mathrm{m}$ thick film, than uncoated tablets fi.e., 100 min for maximum release) (Amin et al. 2012

In another study, Păvaloiu et al. (2015) described the swelling behaviour of mono- and multilayer hydrogels based on BC and gelatin (BC-G). The findings indicated that the swelling of BC-G hydrogels was higher in acidic pH as compared to the basic one due to the polyelectrolyte character of gelatin. Moreover, the concentration of gelatin had a direct relation with the swelling of BC-G hydrogel, while the coating of hydrogel with additional BC has inverse effects on the swelling rate (Pavalloiu et al. 2015). Due to its swelling in acidic condition of the stomach, the

Amin et al. (2014) studied the potential of stimuli-responsive BC-g-poly(acrylic acid-co-acrylamide) hydrogels synthesized by graft copolymerization using the microwave irradiation technique for oral controlled drug deli very (Amin et al. 2014). The hydrogels were suitable for drug that such type of hydrogels may be suitable for drug delivery to the lower parts of the gastrointestinal tract, e.g., peptides, proteins, and acid-labile drugs, and targeted delivery in colonic diseases. In another sustained drug release study, BC-based hydrogels in combination with carboxymethyl cellulose (BC-CMC) were investigated for controlled drug delivery using ibuprofen sodium (IbuNa) as a model drug (Pavaloiu et al. 2014c). The results of this study showed that the CMC content and epichlorohydrin (cross-linker) concentration influenced the swelling and drug release properties of the hydrogels, which were governed by pseudo-Fickian diffusion. These preliminary findings suggested that BC-CMC hydrogels could be exploited as components in controlle
drug delivery applications.

Likewise, mono- and multilayer films of BC, PVA and chitosan (BC-PVA-chitosan) have been reported for controlled release of IbuNa (Paval oiu et al. 2014a). The drug release was pH sensitive, which followed the Fickian model of diffusion. Moreover, the rate of drug release was inversely proportional to the concentration of $\mathrm{BC}$ in the film with pronounced effect in case of multiliayer films. Shi et al. (2014a) fabricated hybrid hydrogels of $\mathrm{BC}$ and sodium alginate (SodAl) as a dual-stimuli-responsive system. The $\mathrm{pH}$ and electric field stimulus-responsive swelling
and drug release behaviours of the $\mathrm{BC}$-SodAl hydrogels were investigated in vitro using lbu as a model drug. The swelling ratio was lower at acidic $\mathrm{pH}$ (less than 8-fold), while higher at alkaline $\mathrm{pH}$ (more than 13 -fold). The electric field of $0.5 \mathrm{~V}$ increased the swelling ratio from 8 -fold (at $0 \mathrm{~V}$ ) to 14-fold. The release of bu was slower in acidic conditions and faster in alkaline conditions (Shi et al. 2014a). Furthermore, the drug release from the BC-SodAl hybrid hydrogels could be boosted with the application of an electric stimulus (Shi et al. 2014a). The BC-SodAl hybrid hydrogels with both pH- and electro-response are therefore new auspicious candidates for oral controlled drug deli very.

Proteinaceous therapeutic candidates have an extended role in several fields of medicine, such as diagnostics, vaccines, inflammatory diseases and cancer (Malik 2008). The increased use of pharmaceutical proteins could be justified by some beneficial properties in comparison to smallmolecule drugs (Vermonden et al. 2012). However, the subtle 3D conformation of proteins is a limitation to the use of such therapeutic candidates due to chemical and proteolytic degradation, aggregation and physical unfolding (Bruno et al. 2013; Manning et al. 1989, 2010; Yang 2015). This kind of instability always results in loss of bioactivity and frequently provokes an immune response (De Groot and Martin 2009; Kal iyaperumal and Jing 2009 ). Furthermore, oral administration of proteinaceous drugs is trickier due to acidic pH and high proteolytic activity of stomach that may lead to destabilization and degradation of the protein structure (Vermonden et al. 2012). In addition, first-pass effect of the liver, fast renal clearance and consequently the short half-lives of proteinaceous drugs require frequent intravenous administration that is
associated with patient's discomfort, incon venience and non-compliance (Harris and Chess 2003 . Tang et al. 2004). Due to the abovementioned limitations, the deli very of proteins is an immense challenge in the field of modern medicine. Fabrication of hydrogels is one of the approach associated with patient's discomfort, inconvenience and non-compliance (Harris and Chess 2003; Tang et al. 2004). Due to the abovementioned limitations, the del
for the improvement of pharmacodynamics and pharmacokinetics of proteinaceous drugs (in intact form) with inproved patient's compliance (Peppas et al. 2004).

BC possesses abundant number of hydroxyl groups in addition to the hydrophilicity and biocompatibility (Pandey et al. 2014; Sulaeva et al. 2015). Such properties enhance the chemical modification capacity with a range of chemical groups, which could modulate the loading and release of drugs from the delivery system. BC has been employed for the oral delivery of protein by fabricating BC-based hydrogels. In this perspective, Ahmad et al. (2014) investigated stimuli-responsive BC-grafted polyacrylamide (BC- - -PAM) hydrogels for oral deli ivery of proteins (Ahmad et al. 2014). In this case, BC- - -PAM hydrogels were fabricated with the help of electron beam irradiation without any cross-linker, thus eradicating any potential toxic effects associated with i (Ahmad et al. 2014). The hydrogels showed potential for protection of bovine serum albumin
(BSA) from gastric (acidic) environment with $<10 \%$ BSA release in simulated gastric fluid (SGF). Moreover, the released BSA was stable and bioactive with enhanced penetration across the intestinal mucosal tissue that was evident from ex vivo penetration experiment. The fabricated (BSA) from gastric (acidic) environment with $<10 \%$ BSA release in simulated gastric fluid (SGF). Moreover, the released BSA was stable and bioactive with enhanced penetration across the intestinal mucosal tissue that was evident from ex vivo penetration experiment. The fabricated
hydrogels were biocompatible, non-toxic and safe for in vivo applications (Ahmad et al. 2014).

Müeller et al. (2013) studied BCM for loading and release of BSA as a model protein for deli very systems. It was demonstrated that the protein release was controlled by diffusion. In this study, the never-dried BC had more protein loading than freeze-dried BC, which might be related to the changes in the fibrous network during the process of freeze-drying (Müller et al. 2013). The study also demonstrated that the integrity and bioactivity of proteins could be maintained during the process of loading and release. In another study, BC and polyacrylic acid (BC-PAA) hydrogels were investigated in vitro for controlled delivery of BSA as model protein (Amin et al. $2012 \mathrm{~b}$ ). The study demonstrated that BC-PAA hydrogels were pH-dependent with lower swelling ratios $(<1000 \%)$ below pH 5 and higher $(>2000 \%$, being maximum) at $\mathrm{pH} 7$. Consequently,
BSA was released in SGF much slower $(15 \%$ at the end of $2 \mathrm{~h}$ ) and faster in simulated intestinal fluid (SIF) $8 \mathrm{~h}$ to release maximum drug for lowest radiation dose and $13-14 \mathrm{~h}$ for the highest) (Amin et al. $2012 \mathrm{~b})$. The difference in release rates as function of $\mathrm{pH}$ were due to the differen BSA was released in SGF much slower $15 \%$ at
swelling rates of BC-PAA due to change in $\mathrm{pH}$.

This clearly demonstrated the potential of BC for pH-responsive delivery system of proteinaceous and non-proteinaceous drugs. Such types of drug delivery systems have the capability for controlled oral delivery of peptides, proteins and acid-labile therapeutic candidates.

Enantioselective drug delivery

Approximately more than $50 \%$ of the drugs in practice exist as racemates and about $90 \%$ of these are marketed as racemic mixtures of an equimolar ratio of two enantiomers (Nguyen et al. 2006). Enantioselective drug deli very and deracemization are $¥$ key processes in modern medicine

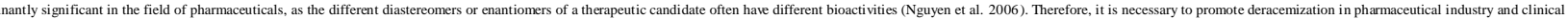
settings to eliminate the unwanted isomer from the product and deliver the desired isomer for optimal treatment, as well as a rational therapeutic control over the patient. In this domain, Bodhibukkana et al. (2006) fabricated BC-based molecularly imprinted polymeric (MIP) matrix system

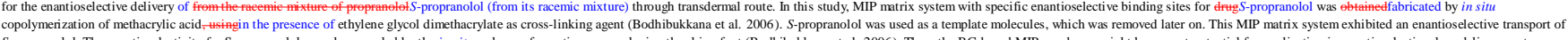
$S$-propranolol. The enantioselectivity for S-propranolol was also revealed by the in vitro release of enantiomers employing the skin of rat (Bodhibukkana et al. 2006). Thus, the BC-based MIP membrane might have great potential for application in enantioselective drug delivery system through transdermal route in clinical settings, and deracemization of racemates of propranolol and other racemic drugs

Dental drug delivery

Dental caries may promote to dental pulp infection, which needs a procedure, known as root canal treatment (RCT), of the affected tooth. The major aim of RCT is to thoroughly decontaminate the root canal system The morphology of root canal is too complex to access in many humans In addition, relapse of dental pulp infections is likewise common. In conventional RCT, a paper point made of PC or cotton pellet is employed in order to dry and sterlize the dental root canal. For such sterilization, high absorbency for residue, high biocompatibility and efficient

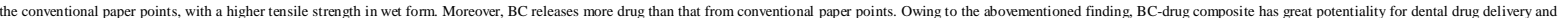
treatment of RCT.

Transdermal drug delivery

Transdermal drug delivery provides an attractive alternate route to both oral drug delivery and hypodermic injection (Prausnitz and Langer 2008; Prausnitz et al. 2004). Since remote times, folks apply different ingredients on the skin for therapeutic purposes, and in the current age, several transdermal formulations have been developed for delivery of drugs to systemic circulation (Prausnitz and Langer 2008). For the same purpose, BCM with and without plasticizer has the potential for trans dermal delivery of therapeutic candidates due to absence of barrier dissuption and erythema (Almeida et al. 2014). In addition, skin moisturizing effect and good skin tolerance further strengthens the reputed interest of BCM as source for trans sdermal drug delivery (Almeida et al. 2014). There are few reports that describe the application of BCM for transdermal drug
delivery. The rate of drug release can also be tailored by controlling the porosity of BC by physical or chemical means and also by changing the hydrophilicity of the environment. For ex ample, a study was carried out by Olyveira et al. (2013), whereby gamma-irradiated and non-irradiated delivery. The rate of dnug release can also be tailored by controlling the porosity of BC by physical or chemical means and also by changing the hydrophilicity of the environment. For ex ample, a study was carried out by Olyveira et al. (2013), whereby gamma-irradiated and non-irradiated
BCM was studied for in vitro drug release in a diffusion cell. It was shown that irradiated BCM has higher pores density than non-irradiated samples, and thus exhibited slower diffusion than the latter one (Olyveira et al. 2013). Likewise, Stoica-Guzun et al. (2007) assessed the effect of electron beam irradiation on the release of tetracycline from BCM as transdermal deli very system. This study showed that electron beam irradiation considerably decreased the in vitro diffusion of tetracycline. These findings suggest the potential of BCM in the form of transdermal patches electron beam irradiation on the release of tetracycline from BCM as transdermal delivery system. This study showed that electron beam irradiation considerably decreased the in vitro diffusion of
(Stoica-Guzun et al. 2007). Hence, it is concluded that the drug release by diffusion can be tuned by treating BCM with ionizing radiations, giving a new way for physical control over drug release.

Likewise, for therapeutic feasibility in terms of transdermal delivery system, BCM was assessed for the in vitro permeation of lidocaine hydrochloride (LHC) and Ibu (model drugs) through human epidermis. The study showed that LHC loaded BCM gave lower permeation rate than that conventional formulations (Trovatti et al. 2012). In contrast, the permeation study for Ibu quite poled apart, as the in vitro permeation rate was almost threefold higher for Ibu-loaded BCM than that of Ibu gel or an Ibu solution in PEG400 (Trovatti et al. 2012). Diclofenac sodium (DS). belonging to the class of NSAIDs, was loaded into BCM (Silva et al. 2014). Using glycerol as plasticizer, BCM was explored as novel nanostructured transdermal delivery systems for DS salt. The drug containing BCM was quite homogeneous and flexible having substantial swelling behaviours. Using human epidermal membranes, in vitro diffusion studies showed that DS loaded BCM had permeation rate comparable to marketed patches of DS and significantly lower than that of a commercial gel formulation (Silva et al. 2014). The simplistic preparation meth
having easy application and the comparable drug release profile clearly demonstrated the enormous potentialities of utilizing BCM in transdermal delivery of DS and other drugs. In a similar context, Pandey et al. (2013) utilized BC dispersion and solution for the preparation of having easy application and the comparable drug release profile clearly demonstrated the enormous potentialities of utilizing BCM in transdermal delivery of DS and other drugs. In a similar context, Pandey et al. (2013) utilized BC dispersion and solution for the preparation of
superabsorbent BC-PAM cross-linked hydrogels by microwave irradiation. The hydrogels exhibited a swelling behaviour (maximum at pH 7). The swelling rate was much higher (ca. 2300-2500 \%) for hydrogels prepared from BC solution than that of BC dispersion (ca. 900 \%). Moreover, the hydrogels sustained the release of theophylline in buffers ( $\mathrm{pH} 7.4)$ for $24 \mathrm{~h}$ (Pandey et al. 2013). The study demonstrates the application of this hydrogel for transdermal delivery of theophylline. However, there is still a need for the in vitro drug permeation studies to further make the
feasibility clearer.

In a recent study, Huang et al. (2013) investigated the BCM for the in vitro controlled druy release of an alkaloid of isoquinoline group, i.e., berberine. In addition to the transdermal controlled drug release experiments, BCM was also tested in SGF, SIF, and acidic and alkaline solution The drug release rate was slower in low-pH fluids (such as SGF), intermediate in alkaline fluid and the highest in near-neutral conditions (such as SIF). The drug release was controlled by diffusion. This type of pH-dependent drug release can be correlated to the swelling of $\mathrm{BCM}$ at

Briefly, in most of the studied systems with BC, the release of the therapeutic candidates was controlled by diffusion. The rates of drug release were temperature- and pH-dependent, where the latter affects the swelling of the nanofibres drastically and thus the porosity of the material is altered (Huang et al. 2013; Pandey et al. 2013).

Macromolecular prodrug delivery

Besides gastric irritation (Radi and Khan 2006), one of the major concerns associated with Ibu is the shorter half-life that needs its most frequent dosing with associated side effects (Wright 2002). To avoid these concerns, researchers have tried some novel pH-dependent conjugates of non-steroidal anti-inflammatory drugs (NSAIDs) with different macromolecules (Hussain et al. 2009; Peng et al. 2006). BC gives more opportunities for modification by different methods due to the presence of abundant surface hydroxyl groups (Stenstad et al. 2008). One of such attempts was made by Shi et al. (2013), who developed a novel BC-based conjugates of Ibu by esterification between - $\mathrm{OH}$ and -COOH groups of BC and Ibu, respectively (Shi et al. 2013). BC-Ibu as a macromolecular prodrug had the capability to control the drug release via the process
of hydrolysis of the ester bond under different pH-conditions. The drug release profiles were dependent on the ester bond hydrolysis, faster in alkaline and acid solution, but relativiely slower in neutral pH (Shi et al. 2013). Such pH-dependent drug release suggests a great potential of BC-lbu as a more effective and stable prodrug candidate. However, this strategy can be further applied to other NSAIDs with carboxyl functional group for the preparation of prodrugg. For example, aspirin could be conjugated to BC to avoid gastric irritation and to target colonic cancer, if the ester bond is sufficiently stable in acidic $\mathrm{pH}$

All the studies discussed above regarding BC-based drug deli very are summarized in Table 3.

Table 3

\begin{tabular}{|c|c|c|}
\hline Purpose & Ther apentic candidate $(s)$ & Strategy \\
\hline \multicolumn{3}{|l|}{ Drug delivery to wound } \\
\hline & BZK & Drug loaded BCM \\
\hline & AMX & Drug loaded BCM \\
\hline & AMP, GM & Drug loaded BCM \\
\hline & GM & $\begin{array}{l}\text { Covalently attached to the surface of } \\
\text { RGDC-modified BCM }\end{array}$ \\
\hline & Tetracycline & Drug loaded BCM \\
\hline & SSD & BCM \\
\hline & Рнмв & BCM \\
\hline & $\begin{array}{l}\text { Deacetylated chitosan, chitosan } \\
\text { montmorillonite }\end{array}$ & вСм \\
\hline & $\begin{array}{l}\text { Metallic nanoparticles (silver, copper, } \\
\text { titanium dioxide) }\end{array}$ & BCM \\
\hline $\begin{array}{l}\text { Tissue engineering drug } \\
\text { delivery }\end{array}$ & & \\
\hline
\end{tabular}




\begin{tabular}{|c|c|c|c|c|}
\hline \multirow[t]{2}{*}{ Purpose } & Ther apentic candidate $(s)$ & Strategy & Finding & References \\
\hline & $\mathrm{BMP}_{2}$ & BC-based protein composite & Biocompatible, and capable of in vitro fibroblast differentiation and bone formation & Shi et al. (2012) \\
\hline \multicolumn{5}{|c|}{ Controlled drug delivery } \\
\hline & Paracetamol & $\mathrm{BC}$ coated tablets & The flexible BC film sustained the drug release & Amin et al. (2012a) \\
\hline & - & BC-based hydrogels with gelatine & Potentials for gastro-retentive drug delivery due to more swelling in acidic conditions & Păvăloiu et al. (2015) \\
\hline & Theophylline & BC-based hydrogels & Lesser drug rele ase in SGF than SIF & Amin et al. (2014) \\
\hline & IbuNa & BC-based hydrogels & pH-dependent sustained druy release & Pavaloiu et al. (2014c) \\
\hline & IbuNa & BC-based hydrogels & pH-dependent sustained drug release & Pavaloiu et al. (2014a) \\
\hline & Ibu & BC-based hydrogels & $\mathrm{pH}$ - and electro-dependent drug release & Shi et al. (2014a) \\
\hline & Propranolol & MIP matrix & Selective transport and release of $S$-propranolol & Bodhibukkana et al. (2006) \\
\hline & BSA & BC-based hydrogels without cross-linker & $\begin{array}{l}\text { Devoid of cross-linker associated toxicity, protection of BSA from gastric conditions, in vitro sustained release of BSA, which was stable after loading } \\
\text { and release }\end{array}$ & Ahmad et al. (2014) \\
\hline & BSA & BCM & More BSA loading in never-dried $\mathrm{BCM}$, and integrity and bioactivity of $\mathrm{BSA}$ was maintained after loading and release & Müller et al. (2013) \\
\hline & BSA & BC-based hydrogels & Lower swelling and lower dug release in acidic pH in comparison to alkaline $\mathrm{pH}$. & Amin et al. (2012b) \\
\hline \multicolumn{5}{|c|}{ Dental drug delivery } \\
\hline & Trypan blue & BC point & Greater drug release in comparison to paper point & Yoshino et al. (2013) \\
\hline \multicolumn{5}{|c|}{ Transdermal drug delivery } \\
\hline & Insulin & ВСм & Gamma-irradiated BCM has slower insulin release than non-irradiated BCM & Olyveira et al. (2013) \\
\hline & Tetracycline & Drug loaded BCM & Electron beam-irradiated BCM has slower tetracycline release than non-irradiated BCM & Stoica-Guzun et al. (2007) \\
\hline & Ibu, LCH & Drug loaded BCM & Slower permeation of LCH than conventional fomulations, faster permeation of lbu than conventional formulations & Trovatti et al. (2012) \\
\hline & DS & Drug loaded BCM & Permeation rate was comparable to commercial patches and significantly lower than commercial gel & Silva et al. (2014) \\
\hline & Theophylline & BC-based hydrogels & Sustained release of theophylline & Pandey et al. (2013) \\
\hline & Berberine & ВСм & Drug release was slower in acidic $\mathrm{pH}$, internediate in alkaline $\mathrm{pH}$ and highest in neutral $\mathrm{pH}$ & Huang et al. (2013) \\
\hline \multicolumn{5}{|c|}{$\begin{array}{l}\text { Macromolecular prodrug } \\
\text { delivery }\end{array}$} \\
\hline & Ibu & pH-dependent ester conjugates & Sustained release of Ibu (faster in alkaline and acid $\mathrm{pH}$, while slower at neutral $\mathrm{pH}$ ) & Shiet al. (2013) \\
\hline
\end{tabular}

Conclusion and future prospects

The current review demonstrates that BC is a natural biomaterial with 'GRAS' status, biosynthesized by non-pathogenic bacteria. BC has great potential for application in food, cosmetics and drug deli very systems, in addition to the aforementioned biomedical applications. Nevertheless

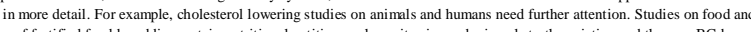
food items. The traditional dessert may also act as a sweetened vehicle for oral drug delivery, particularly for children. Moreover, due to its bulk-forming and water retention capacity, the fibrous nature of the BC-based food products can be assessed for its laxative effect in the treatment of
for constipation. BC can be used in O/W emulsion without surfactant, as a substitute to PC and PC-derivatives. This emulsion could be used for cleansing, makeup, and care or treatment of the lips, skin and the eyelashes, as well as treating certain medical conditions of the skin. Furthemore, a comparison between BC produced under static and agitated conditions should be carried out for pure BC in terms of water uptake for sweat retention in cosmetics, exudate retention in wounds, drug loading, drug release, and fee physical and chemical modifications.

In the modern era, most of the people rely on cosmetics in one way or the other. By addition of antioxidants and therapeutic agents to BC-based cosmetics, a paradigm shift is expected from conventional cosmetics to cosmeceuticals and medicated cosmetics. It is noteworthy that due to it transparency, light transmittance and biocompatibility, BC and/or its hydrogels can be used for the fabrication of disposable and multiple use contact lenses for cosmetic purpose and optometry, and as eetlarimplants for ocular drug delivery

BCM provides a good tool for delivery of antibiotics to the wound with potentials for exudates retention and moisturizing environment that are favourable for wound healing. These studies lack experiments on wound models to study the favourable properties of pristine and antibiotic loaded BCM for in vivo wound healing

The fabrication of BC-based hydrogels has been tested with several polymeric matrices, such as PAA, PVA and PAM. However, many other polymeric biomaterials could be tested while considering specific interactions between carriers and drugs that might tailor the drug release. Despit of several studies regarding the oral deli iery of proteins, only BSA as model protein has been studied. There still exists a space for research entheabout loading, release and stability studies of other proteins with therapeutic value. Regarding transdermal drug del very, BC-based delivery systems have shown promising results in term of biocompatibility (pure BC) with skin, and in vitro drug diffusion studies. However, further in vivo studies for skin irritation potentials of dugg loaded BC and in vivo bioavailability of
drugs from the BC-based delivery systems with and without penetration enhancer(s) are needed.

As discussed in some of the abovementioned studies, drug release is controlled by the process of $\mathrm{pH}$-dependent diffusion, which could be further tailored by additional physical treatments or chemical modifications. Such approaches would enable a sophisticated control over the drug release, particularly in a response to body stimuli, such as temperature above normal, i.e., fever condition and tumour micro-enironment. Moreover, BC-based nanogels would be helpful for invasive targeted delivery of proteinaceous and non-proteinaceous drug, provided that such nanogels are biodegradable in vivo. Such nanogels could also be used in the form of biomolecule-sensitive hyddegels delivery systems, e.g., glucose-sensitive hydrogels for delivery of insulin. Moreover, such biodegradable hydrogels can also be used for targeted drug delivery to tumour
(acidic pH), provided that suitable nanogels are formed that are more sensitive to slight changes for invasive drug delivery. In addition, due to the presence of several-OH groups on its surface, BC has also potential for the formation of macromolecular produg by covalent conjugation. The (microbial esterases

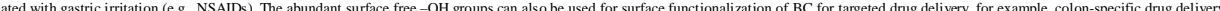

BC alone or in composite form with biocompatible polymer(s) may also find interesting applications in subcutaneous implantable devices for the delivery of therapeutic candidates, where prolonged therapy is desired, such as hormonal replacement therapy and contraception.

In case of MIP, the technique could further be tailored by designing specific MIP to thinffor enantioselective drug delivery ferwith better patient's outcomes, and for enantiomer differentiation and deracemization. Moreover, MIP-based nanoparticulate columns with improved surface are can be designed for efficieient enantiomer separation, anal ysis and deracemization.

In case of all drug delivery systems, discussed in this review, there is a need for further invive studies using various animal models and/or human volunteers for getting a clearer idea about the in vivo performance, bioavailability and in vitro-in vivo correlation (IVIVC) of the prepared delivery system

\section{Acknowledgments}

Hanif Ullah is grateful to Higher Education of Pakistan for fully funded indigenous scholarship (213-62780-2BM2-148) and foreign research sponsorship (RSSIP 30 PS 20) at University of Helsinki, Finland. Dr. H.A. Santos acknowledges financial support from the Academy of Finland (Grants Nos. 252215 and 281300), the University of Helsinki Research Funds, Biocentrum Helsinki, and the European Research Council under the European Union's Seventh Framework Programme (FP/2007-2013) (Grant No. 310892).

References

Ahmad N, Amin MCIM, Mahali SM, Ismail I, Chuang VTG (2014) Biocompatible and mucoadhesive bacterial cellulose-g-poly (acrylic acid) hydrogels for oral protein delivery. Mol Pharm 11:4130-4142

Almeida IF, Pereira T, Silva NH, Gomes FP, Silvestre AJ, Freire CS, Sousa Lobo JM, Costa PC (2014) Bacterial cellulose membranes as drug delivery systems: an in vivo skin compatibility study. Eur J Pharm Biopharm 86:332-336

Amin MCIM, Abadi AG, Ahmad N, Katas H, Jamal JA (2012a) Bacterial cellulose film coating as drug delivery system: physicochemical, thermal and drug release properties. Sains Malays 41:561-568

Amin MCIM, Ahmad N, Halib N, Ahmad I (2012b) Synthesis and characterization of thermo-and pH-responsive bacterial cellulose/acrylic acid hydrogels for drug delivery. Carbohydr Polym 88:465-47,

Amin MCIM, Ahmad N, Pandey M, Xin CJ (2014) Stimuli-responsive bacterial cellulose-g-poly (acrylic acid-co-acrylamide) hydrogels for oral controlled release drug deli very. Drug Dev Ind Pharm 40:1340-1349

Amnuaikit T, Chusuit T, Raknam P, Boonme P (2011) Effects of a cellulose mask synthesized by a bacterium on facial skin characteristics and user satisfaction. Med Devices 4:77-81

Aramwit P. Bang N (2014) The characteristics of bacterial nanocell ulose gel releasing silk sericin for facial treatment. BMC Biotechnol 14:104

Benbow M, Stevens J (2010) Exudate, infection and patient quality of life. Br J Nur 19:S32-S36

Bodhibukkana C, Srichana T, Kaewnopparat S, Tangthong N, Bouking P, Martin GP, Suedee R (2006) Composite membrane of bacterially-derived cellulose and molecularly imprinted polymer for use as a transdermal enantioselective controlled-release system of racemic propranolol. J Control Rel 113:43-56

Bodin A. Concaro S, Brittberg M, Gatenholm P (2007) Bacterial cellulose as a potential meniscus implant. J Tissue Eng Regen Med 1:406-408

Brown AJ (1886a) XIX.-The chemical action of pure cultivations of bacterium aceti. J Chem Soc Trans 49:172-187

Brown AJ (1886b) XLIII._On an acetic ferment which forms cellulose. J Chem Soc Trans 49:432-439

Bruno BJ, Miller GD, Lim CS (2013) Basics and recent advances in peptide and protein drug delivery. Ther Deliv 4: 1443-1467

Butchosa N, Brown C, Larsson PT, Berglund LA, Bulone V, Zhou Q (2013) Nanocomposites of bacterial cellulose nanofibers and chitin nanocrystals: fabrication, characterization and bactericidal activity. Green Chem 15:3404-3413

Campano C, Balea A, Blanco A, Negro C (2015) Enhancement of the fermentation process and properties of bacterial cellulose: a review. Cellulose 23:1-35

Chau C-F, Yang P, Yu C-M, Yen G-C (2008) Investigation on the lipid-and cholesterol-lowering abilities of biocellulose. J Agric Food Chem 56:2291-2295

Chawla PR, Bajaj IB, Survase SA, Singhal RS (2009) Microbial cellulose: fermentative production and applications. Food Technol Biotechnol 47:107-124

Chen X, Chen Z, Zhu J, Xu C, Yan W, Yao C (2011) A novel $\mathrm{H}_{2} \mathrm{O}_{2}$ amperometric biosensor based on gold nanoparticles/self-doped polyaniline nanofibers. Bioelectrochemistry 82:87-94

Chen L, Zou M, Hong FF (2015) Evaluation of fungal laccase immobilized on natural nanostructured bacterial cellulose. Front Microbiol 6:1245

Czaja W. Romanovicz D, Brown RM (2004) Structural investigations of microbial cellulose produced in stationary and agitated culture. Cellulose 11:403-41

Czaja W, Krystynowicz A, Bielecki S, Brown RM (2006) Microbial cellulose-the natural power to heal wounds. Biomaterials 27:145-151

Czaja WK, Young DJ, Kawecki M, Brown RM (2007) The future prospects of microbial cellulose in biomedical applications. Biomacromolecules 8:1-12

Darbre PD. Harvey PW (2008) Paraben esters: review of recent studies of endocrine toxicity, absorption, esterase and human exposure, and discussion of potential human health risks. J Appl Toxicol 28:561-578

De Groot AS, Martin W (2009) Reducing risk, improving outcomes: bioengineering less immunogenic protein therapeutics. Clin Immunol 131:189-201

Dobre ML, Stoica-Guzun A (2013) Antimicrobial Ag-polyvinyl alcohol-bacterial cellulose composite films. J Biobased Mater Bioenergy 7:157-162

Dobre L-M, Stoica-Guzun A, Stroescu M, Jipa I, Dobre T, Ferdeş M, Ciumpiliac \$ (2012) Modelling of sorbic acid diffusion through bacterial cellulose-based antimicrobial films. Chem Pap 66:144-151

Draelos Z. Hornby S. Walters RM, Appa Y (2013) Hydrophobically modified polymers can minimize skin irritation potential caused by surfactant-based cleansers. J Cosmet Dermatol 12:314-321

Dufresne A (2013) Nanocellulose: from nature to high performance tailored materials. Walter de Gruyter, Berlin

Ellis B, Smith R (2008) Polymers: a property database. CRC Press, Boca Raton

Fernandes $\mathrm{P}(2010)$ Enzymes in food processing: a condensed overview on strategies for better biocatal ysts. Enzyme Res. 862537 Article ID 86253 
http://dx.doi.org/10.4061/2010/86253

Fu L, Zhang Y, Li C, Wu Z, Zhuo Q, Huang X, Qiu G, Zhou P, Yang G (2012) Skin tissue repair materials from bacterial cellulose by a multilayer fermentation method. J Mater Chem 22:12349-12357

Gayathry G, Gopalaswamy G (2014) Production and characterisation of microbial cellulosic fibre from Acetobacter xylinum. Indian J Fibre Text Res 39:93-96

Haemmerle G, Signer M, Mittlboeck M (2012) Comparison of PHMB-containing dressing and silver dressings in patients with critically colonised or locally infected wounds. J Wound Care 21:13-19

Harris JM, Chess RB (2003) Effect of pegylation on pharmaceuticals. Nat Rev Drug Discov 2:214-221

Hasan N, Biak DRA, Kamarudin S (2012) Application of bacterial cellulose (BC) in natural facial scrub. IJASEIT 2:1-4

Heath BP, Coffindaffer TW, Kyte III KE, Smith III ED, McConaughy SD (2012) Personal cleansing compositions comprising a bacterial cellulose network and cationic polymer. US patent, US 8097574 B2

Helenius G, Bäckdahl H, Bodin A, Nannmark U, Gatenholm P, Risberg B (2006) In vivo biocompatibility of bacterial cellulose. J Biomed Mater Res A 76:431-438

Huang L, Chen X, Nguyen TX, Tang H, Zhang L, Yang G (2013) Nano-cellulose 3D-networks as controlled-release drug carriers. J Mater Chem B 1:2976-2984

Hubbell JA (1995) Biomaterials in tissue engineering. Nat Biotechnol 13:565-576

Hui J, Yuanyuan J, Jiao W, Yuan H, Yuan Z, Shiru J (2009) Potentiality of bacterial cellulose as the scaffold of tissue engineering of cornea. In: Biomedical engineering and informatics, 2009. 2nd international conference, IEEE, Tianjin, China, pp 1-5

Hussain MA, Badshah M, Iqbal MS, Tahir MN, Tremel W, Bhosale SV, Sher M, Haseeb MT (2009) HPMC-salicylate conjugates as macromolecular prodrugs: design, characterization, and nano-rods formation. J Polym Sci Part A Polym Chem 47:4202-4208

Iguchi M, Yamanaka S, Budhiono A (2000) Bacterial cellulose-a masterpiece of nature's arts. J Mater Sci 35:261-270

Jay JM, Loessner MJ, Golden DA (2008) Modern food microbiology. Springer, New York

Jipa IM, Stoica-Guzun A, Stroescu M (2012) Controlled release of sorbic acid from bacterial cellulose based mono and multilayer antimicrobial films. LWT Food Sci Technol 47:400-406

Jǔzlová P, Martinkova L, Křen V (1996) Secondary metabolites of the fungus Monascus: a review. J Ind Microbiol 16:163-170

Kaliyaperumal A, Jing S (2009) Immunogenicity assessment of therapeutic proteins and peptides. Curr Pharm Biotechnol 10:352-358

Kaplan E. Ince T, Yorul maz E, Yener F, Harputlu E, Laçin NT (2014) Controlled delivery of ampicillin and gentamycin from cellulose hydrogels and their antibacterial efficiency. J Biomater Tissue Eng 4:543-549

Khan T, Park JK, Kwon J-H (2007) Functional biopolymers produced by biochemical technology considering applications in food engineering. Korean J Chem Eng 24:816-826

Khan S, Ul-slam M, Khattak WA, Ulah MW, Park JK (2015) Bacterial cellulose-titanium dioxide nanocomposites: nanostructural characteristics, antibacterial mechanism, and biocompatibility. Cellulose 22:565-579

Kilara A. Shahani KM, Shukla TP (1979) The use of immobilized enzymes in the food industry: a review. Crit Rev Food Sci Nutr 12:161-198

Kirdponpattara S, Phisalaphong M (2013) Bacterial cellulose-al ginate composite sponge as a yeast cell carrier for ethanol production. Biochem Eng J 77:103-109

Klemm D, Schumann D, Udhardt U, Marsch S (2001) Bacterial synthesized cellulose-artificial blood vessels for microsurgery. Prog Polym Sci 26:1561-1603

Klemm D, Heublein B, Fink HP, Bohn A (2005) Cellulose: fascinating biopolymer and sustainable raw material. Angew Chem Int Ed 44:3358-3393

Klemm D, Schumann D, Kramer F, Heßler N, Hornung M, Schmauder H-P, Marsch S (2006) Nanocelluloses as innovative polymers in research and application. Adv Polym Sci 295:49-96

Koohi MK, Hejazy M, Asadi F, Asadian P (2011) Assessment of dermal exposure and histopathologic changes of different sized nano-silver in healthy adult rabbits. J Phys Conf Ser 304:012028

Korani M, Rezayat SM, Bidgoli SA (2013) Sub-chronic dermal toxicity of silver nanoparticles in guinea pig: special emphasis to heart, bone and kidney toxicities. Iran J Pharm Res 12:511-519

Koutinas AA, Sypsas V, Kandylis P, Michelis A, Bekatorou A, Kourkoutas Y, Kordulis C, Lycourghiotis A, Banat IM, Nigam P, Marchant R (2012) Nano-tubular cellulose for bioprocess technology development. PLos ONE 7:e34350

Krystynowicz A, Czaja W, Wiktorowska-Jezierska A, Gonçalves-Miśkiewicz M, Turkiewicz M, Bielecki S (2002) Factors affecting the yield and properties of bacterial cellulose. J Ind Microbiol Biotechnol 29:189-195

Kuehl BL, Fyfe KS, Shear NH (2003) Cutaneous cleansers. Skin Ther Lett 8(3):1-4

Lee CK. Hsu KC, Cho JC, Kim YJ, Han SH (2011) Cosmetic bio-cellulose mask pack sheet and method for manufacturing same. US patent, US 20130244977 Al

Legendre JY (2008) Assembly comprising a substrate comprising biocellulose, and a powdered cosmetic composition to be brought into contact with the substrate. US patent, US $20090041815 \mathrm{Al}$

Levinson DJ, Glonek T (2010) Microbial cellulose contact lens. US patents, US 7832857 B2

Li X. Wan W, Panchal CJ (2010) Transparent bacterial cellulose nanocomposite hydrogels. US patent, US 8940337 B2

Lin K, Lin H (2004) Quality characteristics of chinese-style meatball containing bacterial cellulose (nata). J Food Sci 69:SNQ107-SNQ111

Lin SP, Calvar IL, Catchmark JM, Liu JR, Demirci A, Cheng KC (2013) Biosynthesis, production and applications of bacterial cellulose. Cellulose 20:2191-2219

Lin SP, Hsieh SC, Chen KI, Demirci A, Cheng KC (2014) Semi-continuous bacterial cellulose production in a rotating disk bioreactor and its materials properties analysis. Cellulose 21:835-844

Lin Y-C, Wey Y-C, Lee M-L, Lin P-C (2015) Cosmetic composition containing fragments of bacterial cellulose film and method for manufacturing thereof. US patent, US $20150216784 \mathrm{Al}$

Lin SP, Liu CT, Hsu KD, Hung YT, Shih TY, Cheng KC (2016) Production of bacterial cellulose with various additives in a PCS rotating disk bioreactor and its material property analysis. Cellulose 3:367-377

Lu W, Senapati D, Wang S, Tovmachenko O, Singh AK, Yu H, Ray PC (2010) Effect of surface coating on the toxicity of silver nanomaterials on human skin keratinocytes. Checm Phys Lett 487:92-96

Luan J, Wu J, Zheng Y, Song W, Wang G, Guo J, Ding X (2012) Impregnation of silver sulfadiazine into bacterial cellulose for antimicrobial and biocompatible wound dressing. Biomed Mater 7:065006

LvP, Feng Q, Wang Q, Li G, Li D, Wei Q (2016) Bios ynthesis of bacterial cellulose/carboxylic multi-walled carbon nanotubes for enzymatic biofuel cell application. Materials 9:183

Malik NN (2008) Drug discovery: past, present and future. Drug Discov Today 13:909-912

Manning MC, Patel K, Borchardt RT (1989) Stability of protein pharmaceuticals. Pharm Res 6:903-918

Manning MC, Chou DK, Murphy BM, Payne RW, Katayama DS (2010) Stability of protein pharmaceuticals: an update. Pharm Res 27:544-575

Millon L, Wan W (2006) The polyvinyl alcohol-bacterial cellulose system as a new nanocomposite for biomedical applications. J Biomed Mater Res B Appl Biomater 79:245-25.3

Montealegre CM, Dionisio ER, Sumera LV, Adolacion JR, De Leon RL (2012) A comparison between the performance of S. cerevisiae cells immobilized in nata de coco biocellulose and calcium alginate during continuous bioethanol production. Int J Chem Eng Appl 3:237-242 Mori R, Nakai T, Enomoto K, Uchio Y, Yoshino K (2011) Increased antibiotic release from a bone cement containing bacterial cellulose. Clin Orthop Relat Res 469:600-606

Müller A, Ni Z, Hessler N, Wesarg F, Müller FA, Kralisch D, Fischer D (2013) The biopolymer bacterial nanocellulose as drug delivery system: investigation of drug loading and release using the model protein albumin. J Pharm Sci 102:579-592

Murphy O (2001) Non-polyol low-digestible carbohydrates: food applications and functional benefits. Br J Nutr 85:S47-S53

Nagel JE, Fuscaldo JT, Fireman P (1977) Paraben allergy. JAMA 237:1594-1595

Ng C-C, Shyu Y-T (2004) Development and production of cholesterol-lowering Monascus-nata complex. World J Microbiol Biotechnol 20:875-879

Nguyen LA, He H, Pham-Huy C (2006) Chiral drugs: an overview. Int J Biomed Sci 2:85-100

Nguyen DN, Ton NMN, Le VVM (2009) Optimization of Saccharomyces cerevisiae immobilization in bacterial cellulose by ‘adsorption-incubation' method. Int Food Res J 16:59-64

Nimeskern L, Avila HM, Sundberg J, Gatenholm P. Müller R, Stok KS (2013) Mechanical evaluation of bacterial nanocellulose as an implant material for ear cartilage replacement. J Mech Behav Biomed Mater 22:12-21

Okiyama A, Motoki M, Yamanaka S (1992) Bacterial cellulose II. Processing of the gelatinous cellulose for food materials. Food Hydrocoll 6:479-487

Okiyama A, Motoki M, Yamanaka S (1993) Bacterial cellulose IV. Application to processed foods. Food Hydrocoll 6:503-51

Olyveira GM. Costa LMM. Basmaji P (2013) Physically modified bacterial cellulose as alternative routes for transdermal drug delivery. J Biomater Tissue Eng 3:227-232

Osma JF, Toca-Herrera JL, Rodríguez-Couto S (2010) Uses of laccases in the food industry. Enzyme Res. 91876tArticle ID 91876

http://dx.doi.org/10.4061/2010/91876

Ougiya H, Watanabe K, Morinaga Y, Yoshinaga F (1997) Emulsion-stabilizing effect of bacterial cellulose. Biosci Biotechnol Biochem 61:1541-1545

Pandey M, , Aohd Amin MCIM, Ahmad N, Abeer MM (2013) Rapid synthesis of superabsorbent smart-swelling bacterial cellulose/acrylamide-based hydrogels for drug delivery. Int J Polym Sci. 905477 Article ID 905471 Attp:/dxdoi.org/10.1155/2013/90547/

Pandey M, Mohamad N, Amin MCIM (2014) Bacterial cellulose/acrylamide phpH-sensitive smart hydrogel: development, characterization, and toxicity studies in ICR mice model. Mol Pharm 11:3596-3608

Park JK, Khan T, Jung JY (2009) Bacterial Cellulose. In: Phillips GO, Williams PA (eds) Handbook of hydrocolloids. Woodhead Publishing Ltd., Abington, pp 724-739

Pavaloiu R-D, Stoica-Guzun A, Stroescu M, Jinga SI, Dobre T (2014a) Composite films of poly(vinyl alcohol)-chitosan-bacterial cellulose for drug controlled release. Int J Biol Macromol 68:117-124

Pavaloiu R-D, Stoica A, Stroescu M, Dobre T (2014b) Controlled release of amoxicillin from bacterial cellulose membranes. Cent Eur J Chem 12:962-967

Pavaloiu R-D, Stroescu M, Parvulescu O, Dobre T (2014c) Composite hydrogels of bacterial cellulose-carboxymethyl cellulose for drug release. Rev Chim Buchar 65:948-95

Păvăloiu R-D, Stoica-Guzun A, Dobre T (2015) Swelling studies of composite hydrogels based on bacterial cellulose and gelatin. UPB Sci Bull Ser B 77:54-62 
Peng Y-S, Lin S-C, Huang S-J, Wang Y-M, Lin Y-J, Wang L-F, Chen J-S (2006) Chondroitin sulfate-based anti-inflammatory macromolecular prodrugs. Eur J Pharm Sci 29:60-69

Peppas NA, Wood KM, Blanchette JO (2004) Hydrogels for oral delivery of therapeutic proteins. Expert Opin Biol Ther 4:881-887

Petersen N, Gatenholm P (2011) Bacterial cellulose-based materials and medical devices: current state and perspectives. Appl Microbiol Biotechnol 91:1277-1286

Phisalaphong M, Chiaoprakobkij N (2012) Applications and products-nata de coco. In: Gama M, Gatenholm P, Klemm D (eds) Bacterial nanocellulose: a sophisticated multifunctional material. CRC Press, Boca Raton, pp 143-156

Pinto RJ, Daina S, Sadocco P, Pascoal Neto C, Trindade T (2013) Antibacterial activity of nanocomposites of copper and cellulose. Biomed Res Int. 280512Article ID 280512

Pircher N, Veigel S, Aigner N, Nedelec JM, Rosenau T, Liebnera F (2014) Reinforcement of bacterial cellulose aerogels with biocompatible polymers. Carbohydr Polym 111:505-513

Prabhu BM, Ali SF, Murdock RC, Hussain SM, Srivatsan M (2010) Copper nanoparticles exert size and concentration dependent toxicity on somatosensory neurons of rat. Nanotoxicology 2010:150-160

Prau snitz MR, Langer R (2008) Transdermal drug delivery. Nat Biotechnol 26:1261-1268

Prausnitz MR, Mitragotri S, Langer R (2004) Current status and future potential of transdermal drug delivery. Nat Rev Drug Discov 3:115-124

Purwadaria T, Gunawan L, Agustin GW (2010) The production of nata colored by Monascus purpurreus J1 pigments as functional foods. Microbiol Indones 4:6-10

Qiu K, Netravali AN (2014) A review of fabrication and applications of bacterial cellulose based nanocomposites. Polym Rev 54:598-626

Radi ZA, Khan NK (2006) Effects of cyclooxygenase inhibition on the gastrointestinal tract. Exp Toxicol Pathol 58:163-173

Ratner BD, Bryant SJ (2004) Biomaterials: where we have been and where we are going. Annu Rev Biomed Eng 6:41-75

Ray PC, Yu H, Fu PP (2009) Toxicity and environmental risks of nanomaterials: challenges and future needs. J Environ Sci Health A 27:1-3,5

Ross P. Mayer R, Benziman M (1991) Cellulose biosynthesis and fiuction in becterie Mierobiol Rev 55:35-58

Rouabhia M. Asselin J. Tazi N. Messaddeq Y. Levinson D. Zhang Z (2014) Production of biocompatible and antimicrobial bacterial cellulose polymers functionalized by RGDC grafting groups and gentamicin. ACS Appl Mater Interfaces 6:1439-1446

Rubinstein MP (2003) Applications of contact lens devices in the management of corneal disease. Eye 17:872-876

Samberg ME, Oldenburg SJ, Monteiro-Riviere NA (2010) Evaluation of sil ver nanoparticle toxicity in skin in vivo and keratinocytes in vitro. Environ Health Perspect 118:407-413

Saxena IM. Brown RM Jr (2012) Biosynthesis of bacterial cellulose. In: Gama M, Gatenholm P, Klemm D (eds) Bacterial nanocellulose: a sophisticated multifunctional material. CRC Press, Boca Raton, pp 1-18

Serafica G, Mormino R, Oster GA, Lentz KE, Koehler KP (2010) Microbial cellulose wound dressing for treating chronic wounds. US patent, US 7704523 B2

Shezad O, Khan S, Khan T, Park JK (2010) Physicochemical and mechanical characterization of bacterial cellulose produced with an excellent productivity in static conditions using a simple fed-batch cultivation strategy. Carbohydr Polym 82:173-180 Shi Q, Li Y, Sun J, Zhang H, Chen L, Chen B, Yang H, Wang Z (2012) The osteogenesis of bacterial cellulose scaffold loaded with bone morphogenetic protein-2. Biomaterials 33:6644-6649

Shi X, Zheng Y, Zhang W, Zhang Z, Peng Y (2013) A novel dung carrier based on functional modified nanofiber cellulose and the control release behavior. In: Fourth international conference on smart materials and nanotechnology in engineering. International society for optics and photonics, Gold Coast, Australia, pp 879304-879306

Shi X, Zheng Y, Wang G, Lin Q, Fan J (2014a) pH-and electro-response characteristics of bacterial cellulose nanofiber/sodium al ginate hybrid hydrogels for dual controlled drug delivery. RSC Adv 4:47056-47065

Shi Z, Zhang Y, Phillips GO, Yang G (2014b) Utilization of bacterial cellulose in food. Food Hydrocoll 35:539-545

Shoichet MS (2009) Polymer scaffolds for biomaterials applications. Macromolecules 43:581-59

Silva NH, Rodrigues AF, Almeida IF, Costa PC, Rosado C, Neto CP, Silvestre AJ, Freire CS (2014) Bacterial cellulose membranes as transdermal delivery systems for diclofenac: in vitro dissolution and permeation studies. Carbohydr Polym 106:264-269 Siró I. Plackett D (2010) Microfibrillated cellulose and new nanocomposite materials: a review. Cellulose 17:459-494

Steinemann TL, Fletcher M, Bonny AE, Harvey RA, Hamlin D, Zloty P, Besson M, Walter K, Gagnon M (2005) Over-the-counter decorative contact lenses: cosmetic or medical devices? A case series. Eye Contact Lens 31:194-200

Stenstad P, Andresen M, Tanem BS, Stenius P (2008) Chemical surface modifications of microfibrillated cellulose. Cellulose 15:35-45

Stephens RS, Westland JA, Neogi AN (1990) Method of using bacterial cellulose as a dietary fiber component. US patent, US 4960763 A

Stoica-Guzun A, Stroescu M, Tache F, Zaharescu T, Grosu E (2007) Effect of electron beam irradiation on bacterial cellulose membranes used as transdermal drug delivery systems. Nucl Instrum Methods Phys Res B 265:434-438

Sulaeva I, Henniges U, Rosenau T, Potthast A (2015) Bacterial cellulose as a material for wound treatment: properties and modifications. A review. Biotechnol Adv 33:1547-1571

Suensson A, Nicklasson E, Harrah T, Panilatitis B, Kaplan D, Brittberg M, Gatenholm P (2005) Bacterial cellulose as a potential scaffold for tissue engineering of cartilage. Biomaterials 26:419-43

Tam TTM, Huong NT (2014) Optimization of Corynebacterium glutamicum immobilization process on bacterial cellulose carrier and its application for lysine fermentation. IOSRJEN 4:33-38

Tang L, Persky AM, Hochhaus G, Meibohm B (2004) Pharmacokinetic aspects of biotechnology products. J Pharm Sci 93:2184-2204

Tomé LC, Brandão L, Mendes AM, Silvestre AJ, Neto CP, Gandini A, Freire CS, Marrucho IM (2010) Preparation and characterization of bacterial cellulose membranes with tailored surface and barrier properties. Cellulose 17:1203-1211

Ton N. Le V (2011) Application of immobilized yeast in bacterial cellulose to the repeated batch fermentation in wine-making. Int Food Res J 18:983-987

Tournilhac F, Lorant R (2003) Composition in the form of an oil-in-water emul sion containing cellulose fibrils, and its uses, especially cosmetic uses. US patent, US 6534071 B

Trovatti E, Freire CS, Pinto PC, Almeida IF, Costa P, Silvestre AJ, Neto CP, Rosado C (2012) Bacterial cellulose membranes applied in topical and transdermal delivery of lidocaine hydrochloride and ibuprofen : in vitro diffusion studies. Int J Pharm 435:83-87

Ul-slam M, Khan T, Khattak WA, Park JK (2013) Bacterial cellulose-MMTs nanoreinforced composite films: novel wound dressing material with antibacterial properties. Cellulose 20:589-596

Vermonden T, Censi R, Hennink WE (2012) Hydrogels for protein deli tery. Chem Rev 112:2853-2888

Vowden K, Vowden P (2003) Understanding exudate management and the role of exudate in the healing process. Br J Community Nurs 8:S4-S13

Walters RM, Mao G, Gunn ET, Hornby S (2012) Cleansing formulations that respect skin barrier integrity. Dermatol Res Pract. 495917 Article ID 495917

http://dx.doi.org/10.1155/2012/49591

Wan Y. Gao C, Han M. Liang H. Ren K. Wang Y, Luo H (2011) Preparation and characterization of bacterial cellulose/heparin hybrid nanofiber for potential vascular tissue engineering scaffolds. Polym Adv Technol 22:2643-2648

Wang LP, Wang JY (2014) Skin penetration of inorganic and metallic nanoparticles. J Shanghai Jiaotong Univ (Sci) 19:691-697

Wang W, Li HY, Zhang DW, Jiang J, Cui YR, Qiu S, Zhou YL, Zhang XX (2010) Fabrication of bienzymatic glucose biosensor based on novel gold nanoparticles-bacteria cellulose nanofibers nanocomposite. Electroanalysis 22:2543-2550

Wang T, Long X, Cheng Y, Liu Z, Yan S (2014) The potential toxicity of copper nanoparticles and copper sulphate on juvenile Epinephelus coioides. Aquat Toxicol 152:96-104

Wanling Z, Zhe L, Zerui Z, Bihui Z, Shiyan C, Huaping W, Wen Z (2012) Preparation method for anti-virus bacteria cellulose protective. CN patent, $102321261 \mathrm{~A}$

Wei B, Yang G, Hong F (2011) Preparation and evaluation of a kind of bacterial cellulose dry films with antibacterial properties. Carbohydr Polym 84:533-538

Wen X. Zheng Y, Wu J, Yue L, Wang C, Luan J, Wu Z, Wang K (2015) In vitro and in vivo investigation of bacterial cellulose dressing containing uniform silver sulfadiazine nanoparticles for burn wound healing. Prog Nat Sci 25:197-203

Wonganu B, Kongruang S. (2010) Red bacterial cellulose production by fermentation of Monascus purpureus. In: Chemistry and chemical engineering (ICCCE), international conference, IEEE, Kyoto, Japan, pp 137-141

Wright JM (2002) The double-edged sword of COX-2 selective NSAIDs. CMAJ 167:1131-113

Wu S-C, Lia Y-K (2008) Application of bacterial cellulose pellets in enzyme immobilization. J Mol Catal B Enzym 54: 103-108

Wu S-C, Lia Y-K, Ho C-Y (2013) Glucoamylase immobilization on bacterial cellulose using periodate oxidation method. JSE 3:1-4

Yadav V, Paniliatis BJ, Shi H, Lee K, Cebe P, Kaplan DL (2010) Novel in vivo-degradable cellulose-chitin copolymer from metabolically engineered Gluconacetobacter xylinus. Appl Environ Microbiol 76:6257-6265

Yang M (2015) Stress and protein instability during formulation and fill/finish processes. BioPharm Int 28:46-49

Yano H, Sugiyama J, Nakagaito AN, Nogi M, Matsuura T, Hikita M, Handa K (2005) Optically transparent composites reinforced with networks of bacterial nanofibers. Adv Mater 17:153-155

Yoshino A, Tabuchi M, Uo M, Tatsumi H, Hideshima K, Kondo S, Sekine J (2013) Applicability of bacterial cellulose as an alternative to paper points in endodontic treatment. Acta Biomater 9:6116-6122

Zhang T, Wang W, Zhang D, Zhang X, Ma Y, Zhou Y, Qi L (2010) Biotemplated synthesis of gold nanoparticle-bacteria cellulose nanofiber nanocomposites and their application in biosensing. Adv Funct Mater 20:1152-1160

Zhong CY (2008) Bacterial cellulose gel face mask. CN patent, 200610075040

Zimmermann KA, LeBlanc JM, Sheets KT, Fox RW, Gatenholm P (2011) Biomimetic design of a bacterial cellulose/hydroxyapatite nanocomposite for bone healing applications. Mater Sci Eng C 31:43-49 